\title{
Teaching Public Speaking in the UAE
}

\author{
Lyall Crawford
}

Zayed University, Abu Dhabi

The purpose of this essay is to provide a personal narrative about COM 230: Public Speaking and Professional Presentation offered in the College of Communication and Media Sciences at Zayed University (ZU). It is taken and amended from my faculty evaluation portfolio and it consists of my responses to questions that direct a self-evaluation of teaching effectiveness in this particular course. These remarks are intended to be helpful for instructors who are responsible for public speaking and related courses in the Gulf region, in addition to giving some pedagogical and cultural comments of a more general nature.

\section{Course Objectives}

COM 230 is a basic public speaking course, and the first class in this area that students take in our College. There is an advanced public speaking course offered in our curriculum but, to my knowledge, this course has never actually been offered. I normally shy away from teaching basic public speaking but in the cultural setting of Zayed University I believe this course is an important one for our students. They face an additional challenge in that, for most of them, English is not the first language they learned. The ability to speak intelligently, coherently, and effectively in front of an audience is a difficult task for many people and this is, I think, especially the case when speaking in a language that is not the first learned. Consequently, I do what I can to assist the students enrolled in this class to develop their competence and confidence as public speakers.

I have already alluded to one of my objectives for this course; namely, the ability to speak effectively in front of an audience. Speaking effectively is closely associated with sound thinking, so another objective of this course is to provide a setting where students can gain proficiency in presenting information and arguing a position based on skillful research and responsible knowledge. All the fundamental principles of good public speaking are addressed in COM 230: dealing with communication anxiety, topic selection, adapting to the audience, researching and structuring a speech, using language effectively, outlining a speech, effective use of visual aids, constructing arguments, informative and persuasive speaking, and so on. When students finish this course, they are expected to have reached adequate levels in all of these areas and to be proficient in the preparation, practice, and presentation of public speeches.

The students at ZU seem quite experienced in presenting group projects; it appears that course requirements across the disciplines often include group presentations. In light of this, there is a tendency to approach a public speech the way they approach a group presentation, and this sometimes leads to difficulties because the two are not the same. The group presentations I've seen seem quite informal, and often include the audience in a workshop-kind-of-way. What I/we try to do in the public speaking course is get students away from the "Hello everyone! My name is Fatima" cliché approach to public speaking, and replace this style with a fairly structured public presentation that is purposeful, well researched, and substantive. I'm not suggesting that group presentations necessarily lack these characteristics; I'm merely asserting that public speaking requires particular abilities that attempt to accomplish particular ends with an audience in a public setting. The purpose of COM 230 is to equip our students with these abilities. 
Let me also mention an objective I have for all my classes - increased peace of mind. I hope that when students finish courses we've experienced together, all of us have learned something that will help us have more satisfying and contented lives.

\section{Student Population}

The students at ZU are female UAE nationals. The students in COM 230 are typically communication majors in their first or second semester of the program. This is a core course in our curriculum, so students are there because they have to be to complete our program requirements. All three concentrations of the major are often represented in any given section of COM 230, and increasing numbers of students from other majors are taking this public speaking course. It's conceivable this course might become something like a service course for the entire university.

I've already mentioned that I think ZU students get considerable practice making classroom presentations, and I think they are often exposed to some of the rudiments of public speaking as well. I say this because there seems to be a generally shared "style" of speaking in front of an audience that gets brought into the COM 230 classroom, a style that is less formal and way too reliant on Power Point slides than what I'd like them to be able to do when they finish this course. There is also a tendency to read material downloaded from the Internet instead of speaking extemporaneously. So, although there may be practiced speakers entering this class, it is generally the case that what they expect from this course may differ from what they will be required to accomplish.

\section{Strategies and Techniques to Accomplish Learning Outcomes}

COM 230 is approached more-or-less traditionally; that is, a portion of our class time is devoted to short lectures and discussions about public speaking issues. Instead of major exams, I use quizzes usually administered just before a speech round and after two or three chapters in the text had been considered. In-class activities and worksheet assignments geared toward informative and persuasive speaking are also used to move us towards the objectives of this course. I make a special effort to facilitate classroom discussions and I use a number of non-graded speaking activities to provide an experiential sense of what it's like to speak in front of an audience. A few students enrolled in this class are often surprised by the degree of anxiety they experience during the initial phases of these activities. However, it has not been the case that anyone becomes inordinately uneasy with this aspect of the course.

\section{Assessment}

Recently, a former student told me I should be more strict in class. I do tend to interpret the ZU attendance policy in as relaxed a way as possible, and I'm uneasy with being an enforcer in the classroom. I realize this may seem unfair to students who come to class on time, hand in assignments when they are due, and are generally responsible and serious about their studies. But I've also discovered that the majority of students do come through with what is expected even though I give them lots of room to behave otherwise.

I use common methods of assessing student competence in this course - quizzes, worksheets, the speeches themselves, outlines, in-class activities, participation, and the like - and I believe I am able to get a pretty good sense of how well each student is progressing as we work our way through the 
semester together. For me, the process of evaluating is my least favorite responsibility as a teacher but I certainly realize its importance and I do it as well as I can. This said, I also realize I don't assess students as well as I might and, consequently, I've been attending a series of presentations offered by the Center for Teaching and Learning at Zayed University addressing the issues of assessment and how to match intended outcomes with methods of evaluation.

Incidentally, to hedge against grade inflation I conduct one-to-one conversations with each student whenever a graded assignment is handed back. I place the grade at the very back of the assignment (worksheet/ speech critique/ quiz), and work through the entire assignment with the student point by

point. Typically, by the time we reach the end of our conversation at the conclusion of working carefully through the assignment, disagreements have been managed and there is usually consensus about the evaluation. I find this method eliminates virtually all the reactivity that often occurs if assignments are returned to the class as a whole and students just look at their grade and find it lacking. One class period of roughly 90 minutes usually suffices for a class of 15-20 students. While I talk with each student, the rest of the class work on a task or activity I have provided; I realize this may not be feasible for large classes. In addition to talking about the assignments per se, these conversations also provide a forum for explaining how I interpret the letter grades, and for pointing out that hard work doesn't necessarily translate into a good grade - a belief that seems quite common among the students I have taught in the Gulf region.

So, overall, I believe I have a fairly decent sense of how well students in COM 230 are accomplishing the objectives stated in the syllabus. In years past, I may have been too lenient in terms of what I set out as learning and teaching goals. Recently, however, I've been raising the bar and asking for better research and speech delivery performances from students in this class. The assessment presentations I've been attending, coupled with my formal education and considerable experience in the classroom, should help me continuously improve my ability to gauge how well students accomplish course objectives.

\section{A Little of What l've Learned}

I consider myself a reasonably good and experienced teacher, but I also know I can do much, much better in the classroom. Furthermore, overseas teaching convinces me that cultural differences can present real challenges for student and instructor alike. In fact, it's quite possible that cultural differences are never really transcended inside or outside the classroom. It may be the case that the only culture we truly live and understand (consciously and subconsciously) is our own - the culture we were born into, the culture that shaped us during our very early years, and the culture that shapes us still. (It is also the case, I believe, that more and more infants are being born into multi-cultural worlds.) This said, let me add that I also believe we can effectively interact with one another despite our cultural differences and misunderstandings. Consequently, l've learned that cultural differences can be recognized, accepted and effectively used as sites of learning in the classroom.

I've also learned that it is better to get a sense of where students are and then attempt to help them improve. This is certainly not an original insight, but it is important to keep in mind because it focuses the educational enterprise on the learner rather than the teacher. I'm not saying that instructors should totally give up their agenda and standards and think only of their students and what they would like to do in the classroom. This would be silly and forfeit an important reason for education (and indoctrination?) in the first place. I'm merely mentioning the importance of adapting to circumstances and altering the syllabus accordingly. It does no good to conduct a course that is completely out of reach for the students taking it, particularly if this is because of language ability. Better, instead, to 
adapt and collaborate as extensively as possible and teach in a way that is accessible while still being challenging and credible.

Furthermore, I believe it is better if I stop being so self-conscious and self-deprecating about the fact I'm an English-only-person (with the merest smattering of market Mandarin). I think there are times in the classroom when I make too many allowances for the English of my students because I so appreciate and admire that they are interacting and learning in a language that, for most of them, isn't their own. I think I can assist them more if I hold them to higher standards of English language ability. This is another thing I've learned and I believe doing this will make the classroom experience a better one for all of us.

Finally, it probably goes without saying that, due to my US background, whenever I walk into a classroom with students who possess a cultural heritage different from my own, the course I'm "teaching" is a course in the culture of the United States, whatever the specific subject matter may be. This said, I think it's also a good idea to remain aware of local cultural influences and to connect course content to local knowledge whenever this can be done gracefully and appropriately in a manner that strengthens the course. Global awareness can be an important facet of a course that relies primarily on Western rhetorical traditions. But a public speaking class can also acknowledge and appropriate local ways of speaking in public.

\section{Author}

Lyall Crawford is Professor of Communication and Media Sciences at Zayed University, UAE. He recently returned to Zayed University after two years as a visiting professor in the Department of Communication Studies at Tzu Chi University in Hualien, Taiwan. His research interests include ethnography and ethnographic fiction, as well as intercultural communication; his teaching interests include student-centered pedagogy, symbolic worlds and human sense-making. 